\title{
LA HIPERSEXUALIZACIÓN DE LA MUJER EN LOS 14 CAÑONAZOS BAILABLES
}

\section{THE HYPEREXUALIZATION OF WOMEN IN THE 14 DANCING CANYONS}

\author{
Karen Liliana Urueña Montero ${ }^{1}$ \\ Javier Elias Eslava Orozco \\ Universidad Pedagógica y Tecnológica de \\ Colombia, Tunja - Boyacá
}

\section{RESUMEN}

El presente artículo tiene por objetivo identificar las representaciones sociales del cuerpo de la mujer colombiana en los años 60 s y 70 s, construidas a partir de la cosificación y los discursos sexualizados, y la manera en que estos generan la naturalización de cotidianidades regidas por prácticas patriarcales. La importancia de esta propuesta recae en la necesidad de analizar los factores que históricamente han reforzado los discursos de marginalidad sobre

$1 \quad$ Abogada, especialista en Gestión Pública, maestranda en Derechos Humanos, investigadora del grupo Reconciliación con la Justicia y la Dignidad Humana - Red Humana, de la Universidad Pedagógica y Tecnológica de Colombia, Tunja - Boyacá. Karen. uruena@uptc.edu.co. 31221005 88. https://orcid.org/0000-00023143-2768

2 Licenciado en Ciencias Sociales, candidato a magister en Derechos Humanos, investigador del grupo Primo Levi en Justicia Social, de la Universidad Pedagógica y Tecnológica de Colombia, Tunja - Boyacá. Javier.eslava@uptc.edu.co. 3143033288. https:// orcid.org/0000-0002-6249-8874 la mujer en Colombia, y así generar propuestas enfocadas en identificar las problemáticas y posibilitar soluciones y alternativas. Sobre esta perspectiva investigativa, se analiza la representación gráfica que aparece anualmente durante la época decembrina, en cuyas carátulas de producción discográfica distribuidas públicamente y denominada 14 Cañonazos Bailables; la casa disquera colombiana Discos Fuentes, durante los últimos 60 años, de manera ininterrumpida, ha hipersexualizado y cosificado el cuerpo de la mujer en sus portadas como estrategia mercantil.

Desde la perspectiva metodológica, este artículo aborda la problemática de la cosificación de la mujer, desde el análisis documental de tipo cualitativo que observa los discursos patriarcales impuestos al rol social de la mujer; de igual manera como fuentes de investigación 
tanto primarias y como secundaria, se trabaja el análisis de documentos gráficos y la revisión bibliográfica. Se recurre al análisis semiótico de las carátulas de los discos 14 Cañonazos Bailables, con el propósito de interpretar los mensajes implícitos y explícitos que proyectan las imágenes que ambientan las portadas. Este proceso de observación contribuye a la descodificación de los mensajes que a través de códigos de dominación del cuerpo de la mujer se legitiman en la sociedad colombiana, traducidos en discursos sexualizados, que normalizan las micro violencias cotidianas.

\section{PALABRAS CLAVE}

Mujer, Hipersexualización, Cosificación, Roles sociales, Publicidad.

\section{ABSTRACT}

The objective of this article is to identify the social representations of the body of Colombian women in the 60 s and 70 s, built from the objectification and sexualized discourses, and the way in which these generate the naturalization of everyday life governed by patriarchal practices. The importance of this proposal lies in the need to analyze the factors that have historically reinforced the discourses of marginality about women in Colombia, and thus generate proposals focused on identifying the problems and enabling solutions and alternatives. On this investigative perspective, the graphical representation that appears annually during the Christmas season is analyzed, in whose album covers of publicly distributed production and called 14 Cañonazos Bailables; For the past 60 years, the colombian record house Discos Fuentes has continuously hypersexualized and objectified the body of women on its covers as a commercial strategy.

From the methodological perspective, this article addresses the problem of the reification of women, from a qualitative documentary analysis that observes the patriarchal discourses imposed on the social role of women; In the same way, as both primary and secondary research sources, the analysis of graphic documents and the bibliographic review are worked on. The semiotic analysis of the album covers is used 14 Cañonazos Bailables, with the purpose of interpreting the implicit and explicit messages projected by the images that set the covers. This observation process contributes to the decoding of the messages that through codes of domination of the woman's body are legitimized in Colombian society, translated into sexualized discourses that normalize daily micro-violence.

\section{KEY WORDS}

Woman, Hypersexualization, Objectification, Social roles, Advertising.

\section{INTRODUCCIÓN}

En la actualidad, el rol social de la mujer se encuentra delimitado por lógicas derivadas del régimen patriarcal, las cuales, por medio de semióticas de representación social, cosifican su cuerpo, relegando a significantes de dominación que le impiden la autogestión y la autodeterminación. Por tal motivo, se hace indispensable partir del análisis sociológico del rol desempeñado por la mujer como figura publicitaria en los años 60 y 70 en Colombia, dentro de las carátulas de los discos 14 Cañonazos Bailables, y tomando como sustento las representaciones sociales, que han permitido la vulneración de los Derechos Humanos de las mujeres, convirtiéndola en motivo de discursos agenciados por el deseo masculino. De manera que se logre identificar cómo las representaciones sociales del cuerpo de la mujer colombiana construidas a través de los discos 14 Cañonazos Bailables, han propiciado la cosificación e hipersexualización de la mujer en Colombia. 


\section{MUJER COSIFICADA}

En la cotidianidad, la mujer se enfrenta a imágenes publicitarias que hacen de su cuerpo un objeto de intercambio, otorgándole simbólicamente, un rol social enmarcado en la obligación de satisfacer las necesidades del mercado, relegadas a servir como objetos de transacción o cambio, igual que se hace con los signos, las deudas y las mercancías, siendo una manifestación plausible de las lógicas que gobiernan la producción capitalista globalizada y la gestión de los comportamientos dentro del patriarcado.

La cosificación de la mujer es percibida con naturalidad ante la sociedad, limitándose a ser un objeto de deseo en el que se crea una expectativa irreal sobre la belleza, tal como Lopez, V (2019), lo ha planteado:

La publicidad y los medios de comunicación contribuyen a la representación social de un cuerpo 'ideal' y proporcionan continuamente un referente en el cual compararse. Los valores que se asocian al cuerpo femenino se encuentran relacionados con: belleza, juventud y delgadez. Una proyección a imitar cada vez más ilusoria debido a los avances tecnológicos que pueden derivar en riesgos para la salud. Gran parte de esta percepción se encuentra mediatizada por la publicidad y la moda, referentes que conducen hacia lo que es bello, atractivo y exitoso. (p.22)

Por otro lado, es importante analizar cómo el cuerpo de la mujer ha sido objetivado dentro de la publicidad y los mass media, en donde se ha relegado su papel a ser un objeto de intercambio y de deseo del que no es parte activa, frente a esto Sotelo \& Dominguez (2014) mencionan que:
En el terreno de los mass media en general y de la publicidad en lo particular, donde encontramos una sobreexplotación del cuerpo femenino y una mirada donde la masculinidad sigue siendo hegemónica. Simbólicamente, la publicidad, las telenovelas, el cine, las revistas y demás, son generadoras de aquellas fuerzas invisibles que legitiman y reproducen los símbolos culturales predominantes en el llamado nuevo orden mundial de la comunicación y la información (p. 41)

En este orden de ideas, "Las mujeres se encuentran en la situación de emplear la belleza y la deseabilidad como fuente de poder, haciéndolas dependientes de una mirada masculina y pudiendo acabar resultando ser una trampa" (Walter, 2010).

Por su parte, González, A y Rorrado E. (2018), en su artículo Cosificación y mercantilización de las mujeres: las tecnologías como instrumento de violencia, mencionan que:

La cosificación hace referencia al proceso de construcción social por el cual todas las mujeres, constituyen un todo homogéneo y no heterogéneo, diversos y con agencia. Por el contrario, se objetiviza a las mujeres y sus cuerpos como si fueran cosas, se las desprovee de agencia, negando su diferenciación y rol de sujetos y actores políticos. (p. 2)

Es pertinente ahora realizar una relectura desde la teoría feminista del contrato social, en el que el varón de la modernidad triunfa sobre la sociedad primitiva, en la que se plantea la aniquilación del monopolio del placer de la ley del padre primigenio y la instalación del patriarcado fraternal moderno, que le permite a las sociedades de hermanos, danzar sobre el cadáver del padre derrotado, disponiendo a su antojo del cuerpo de las mujeres. Así las cosas, Piccone (2018) afirma que: 
La comunidad rousseauniana que encadena a todos los integrantes en pos del beneficio común, encadena a las mujeres doblemente porque quedan sometidas a un gobierno que no conformaron y a un amo en el ámbito privado. En el contrato social rousseauniano, los varones pactan su libertad y el sometimiento de las mujeres. (p.151)

De esta manera, la mujer se ha convertido en un objeto de intercambio en la que solo son la parte pasiva del trato, Irigaray (2009), en su libro Ese sexo que no es uno, ha planteado como la mujer es usada como intercambio y riqueza:

El intercambio de mujeres como bienes, acompaña y estimula los intercambios de otras «riquezas» entre los grupos de hombres. De esta suerte, la economía en sus sentidos tanto estricto como general, tal y como está establecida en nuestras sociedades exige que las mujeres se presten a la alienación en el consumo y a los intercambios sin participación en los mismos, y que los hombres queden exentos del uso y de la circulación como mercancías. (p.129)

Para pensadoras y activistas de la teoría feminista como Carole Pateman, Luce Irigaray y Celia Amorós; es en las sociedades primitivas que se instala el discurso patriarcal y su cultura de representación de la mujer como objeto de intercambio, siendo excluidas de la cacería y la guerra, actividades que producían valor simbólico y posicionamiento político, para ser confinadas a actividades propias del hogar y la reproducción, bajo el estatuto de lo innoble y desdeñable.

Por su parte, la historiadora Lerner (1986) precisa que el patriarcado es: "la manifestación e institucionalización del dominio masculino sobre las mujeres y niños/as de la familia y la ampliación de ese dominio sobre las mujeres en la sociedad en general", además, menciona que desde el inicio de la civilización retomando a Mesopotamia "el dominio patriarcal sobre la familia adoptó multiplicidad de formas: la autoridad absoluta del hombre sobre los niños, la autoridad sobre la esposa y el concubinato".

Por otra parte, para Navarro, O., y Restrepo, D. (2013), en su artículo Representaciones Sociales: perspectivas teóricas y metodológicas, mencionan que: "una Representación Social es el resultado de la relación entre un objeto (algo o alguien o un evento) de representación y de un sujeto que lo representa (individuos y grupos) dentro de un marco histórico y cultural de referencia."(p.20) Siendo así, las Representaciones Sociales son estructuras del pensamiento construidas socialmente, con la intencionalidad de permitir la comunicación y socialización entre integrantes de un grupo social, e incluso con integrantes de grupos sociales distintos.

Si bien en Colombia se han realizado importantes avances en materia normativa frente a los derechos de las mujeres, es preciso mencionar que el sistema jurídico-normativo colombiano no logra responder a las necesidades de garantizar los derechos a las mujeres en un contexto de violencia como el que vive el país. Rita Segato (2016) en su libro La Guerra Contra las Mujeres comenta que, para Elizabeth Odio:

Los derechos de las mujeres están definidos como: "un conjunto de intereses y necesidades de la población femenina surgidas del debate promovido desde la perspectiva de género y que, en el contexto de los derechos humanos, constituyen una ampliación de los derechos humanos de forma específica". (Consejería para la Equidad de la mujer, 2014) 


\section{UNA MIRADA EN RETROSPECTIVA}

En la historia de la humanidad, el deseo ha tenido imagen de hombre. Han sido los deseos masculinos los que han dominado las ideas y las acciones para satisfacerlos. Se pueden encontrar derechos constituidos como norma ya sea por medio de la costumbre o de las leyes. El viejo aparato jurídico-normativo, impuesto por el patriarcado, permitió gestionar los comportamientos sociales del cuerpo de la mujer. Las tecnologías de poder mediático y su asepsia productiva inauguraron una anatomopolítica molecular refractaria, siendo los nacientes medios de entretenimiento los encargados de encauzar, normalizar y gestionar lo que ellas deben representar, con la intención de minimizar la colateralidad y propiciar la utilidad de su cuerpo. El cuerpo de la mujer es el resultado del deseo histórico del hombre.

Los códigos de dominación del cuerpo de la mujer en Colombia, impuestos por discursos sexualizados, han conllevado a la naturalización de microviolencias cotidianas, yala consolidación de su cuerpo bajo las coordenadas del régimen patriarcal, excluyendolas de la posibilidad de la autodeterminación; por tal motivo, se hace indispensable analizar la situación actual de la mujer en Colombia, tomando como sustento las regulaciones normativas, las representaciones sociales, que han permitido la construcción social de la mujer como discurso agenciado por el deseo masculino, de manera que se comprendan los factores que determinan su exclusión, invisibilidad y cosificación.

Por tal razón, es necesario analizar los factores que históricamente han reforzado los discursos de marginalidad sobre la mujer en Colombia, y realizar investigaciones que se enfoquen en identificar las representaciones sociales que se han naturalizado en la cotidianidad, impidiendo reconocer la importancia de la función social de la mujer colombiana.

\section{DESCONSTRUCCIÓN Y DECODIFICACIÓN DE LA IMAGEN PUBLICITARIA}

En este sentido, esta investigación parte de la tesis de que la imagen está estructurada como lenguaje, la cual se debe decodificar para lograr traducir o interpretar las intencionalidades veladas de enunciación. Para cumplir con estas exigencias, se deconstruye semióticamente las carátulas de la publicidad sexista en Colombia presente en los 14 Cañonazos Bailables -específicamente de los años 60 y 70-por medio del análisis de la imagen y de su estructura plástica: el color, las formas, la luz, los objetos, etc., atendiendo a las situaciones semánticas que se exteriorizan por medio del concepto de falo sublimado, el cual, se lo asume, como sustituto simbólico que manifiesta la presencia real del estatuto masculino. De esta manera el objeto manifiesto del deseo masculino se encuentra implícito dentro de la imagen, de tal manera que, el falo sublimado se instituye como significante que devela las pretensiones dominantes sobre el cuerpo femenino. Este exilio material se representa en objetos o gestos que ponen en juego la sustitución y la dramatizan en objetos materiales de orden fálico. En este sentido, el falo sublimado permite materializar el fantasma (deseo masculino) y ponerlo en evidencia, demostrando cómo la imagen recrea formas de exclusión y dominación sobre el cuerpo de la mujer: La mujer como mercancía. El estatuto masculino se transfiere al objeto- simulacro y dramatiza la teatralidad de la imagen.

Las actuales condiciones sociales del país demuestran la necesidad de analizar los enunciados que emergen en los discursos publicitarios. Un ejercicio arqueológico, que para este caso de estudio se centra en los años 60 y 70 , que comprende los 20 primeros volúmenes de los discos 14 Cañonazos Bailables, los cuales llevan a entender las distintas posturas ideológicas en el espectro político y cultural nacional, así como los imaginarios circulantes 
que permean y determinan la emotividad con la que las y los ciudadanos consumen la información y la distribuyen en sus zonas de interacción.

En este contexto, es preciso indagar los procesos de enunciación que han posibilitado instalación del cuerpo de la mujer dentro del escenario publicitario, analizando la performance verbal o lingüística que hace parte de los 14 Cañonazos Bailables comparándola con los discursos de emancipación y los discursos de oposición que les niegan; con la finalidad de comprender la hipersexualización de la mujer en Colombia como resultado no sólo de hechos tangibles de cosificación, sino también como producción deseante de discursos que legitiman la violencia y que hoy sirven como caldo de cultivo de la violencia machista, ya que la creación de discursos de negación de la otredad precede a la configuración de la violencia como forma de exterminio de la mujer.

Siendo así, este artículo analiza a través de la imagen, la comprensión de los enunciados de sometimiento que han prevalecido históricamente en la publicidad nacional y que han sido consumidos y reproducidos a-críticamente por la sociedad, un ejercicio de comunión inscrito en la estética del perdón y la ética de la reconciliación.

\section{Los 14 Cañonazos Bailables son la} representación de la cultura popular decembrina, en el que se consignan los éxitos musicales del año, estos discos tienen su origen en 1961, año en el que la reconocida casa discográfica Discos Fuentes, en cabeza de su fundador Antonio José Fuentes López, lanza un compilado anual que incluirá los éxitos de reconocidos cantantes como el Joe Arroyo, Calixto Ochoa, Lizandro Mesa y Rodolfo Aicardi, y grupos musicales como Fruko y sus Tesos, Los Tupamaros, Los Corraleros del Majagual y The Latin Brothers; posicionándose en el mercado colombiano como uno de los discos más esperados en el año, al punto estar presente en gran parte de los hogares colombianos.

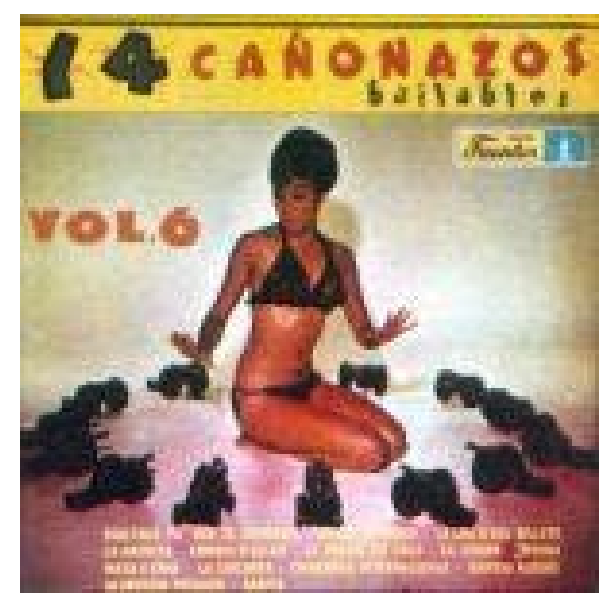

Fig 1. 14 Cañonazos Bailables [Caratula], Discos Fuentes 1966. Tomado de: https:// discosfuentes.com.co/14-canonazos bailables/\#1482124967134-ef576fcc-660a

En sus inicios, las carátulas de los 14 Cañonazos Bailables mantenían un diálogo con el cañón. En los volúmenes uno y dos se puede apreciar como estos objetos bélicos se presentan como protagonistas principales de la imagen. La representación del cañón como objeto fálico se manifiesta desde sus inicios. Entre el volumen 1 y 2 solo hay un pequeño cambio en las tonalidades usadas. El concepto visual es el mismo. Para el volumen cuatro, se toma la misma fotografía del anterior volumen, con la diferencia de que la mujer ha sido sustituida por un recuadro blanco; la corporeidad de la mujer desaparece, solo hace parte de los deseos masculinos. Para el volumen 5, la mujer y el cañón comparten protagonismo en la fotografía, ya no hay hombre concreto, se ha diseminado en la totalidad simbólica de la imagen. La mujer enciende el deseo masculino de igual manera que prende el cañón. En el Volumen 6, la mujer es rodeada de cañones, los cuales apuntan peligrosamente a su cuerpo. Múltiples falos erguidos ante su figura la rodean, sometiéndola al exilio de la propiedad perdida. La diagramación y composición de esta imagen pone de mani- 
fiesto el mandato masculino, la mujer carece de libertad, es proscrita y expulsada de su cuerpo, habitando el deseo masculino, el cual la instiga a la pérdida simbólica y real de su estatus.

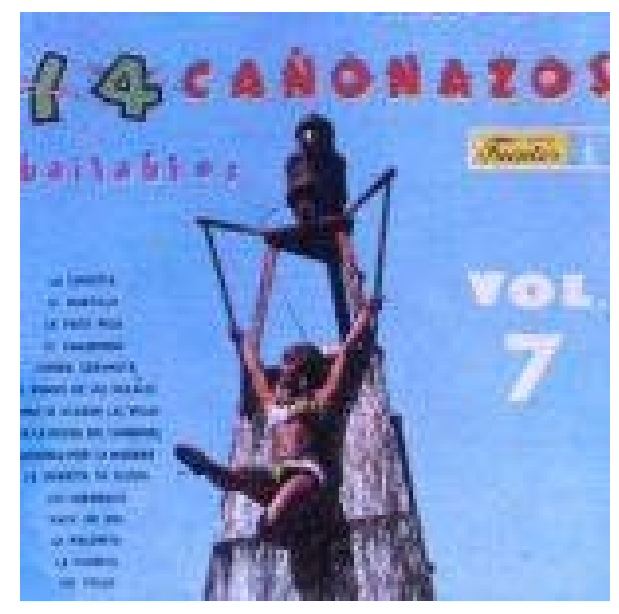

Fig 2. 14 Cañonazos Bailables [Caratula], Discos Fuentes 1967. Tomado de: https:// discosfuentes.com.co/14-canonazos bailables/\#1482124967134-ef576fcc-660a

Para el volumen 7, la mujer se encuentra en una posición de sometimiento, en que su cuerpo se convierte en el principal anfitrión. Más adelante, en el volumen 9, la figura de esta mujer se reduce a la imagen de su bikini, sin tener tan siquiera un rostro. Asimismo, el volumen 11 aparece la imagen de la mujer en una posición seductora, en la cual se resalta su cuerpo debido a la poca ropa que la acompaña. De igual manera, en el volumen número 13 , se presenta una mujer joven, la cual se destaca por tener una figura estilizada, voluptuosa y erguida.

Posteriormente, en el volumen número 19 se representa un proceso de americanización de la mujer, debido a que se plasma a esta con rasgos particulares tales como cabello rubio, cuerpo estilizado y tez aria, además de encontrarse en una posición sugestiva y falocéntrica, por último, el volumen número 20 , lanzado al mercado en 1980, deja a un lado las prendas que en volúmenes anteriores acompañaban a las mujeres y exhiben una mujer completamente desn- uda que tapa su cuerpo con su propia carne. Imágenes que refuerzan las teorías anteriormente abordadas, en las que la mujer se ve relegada a una representación social fundada en su cuerpo hipersexualizado y mercantilizado.

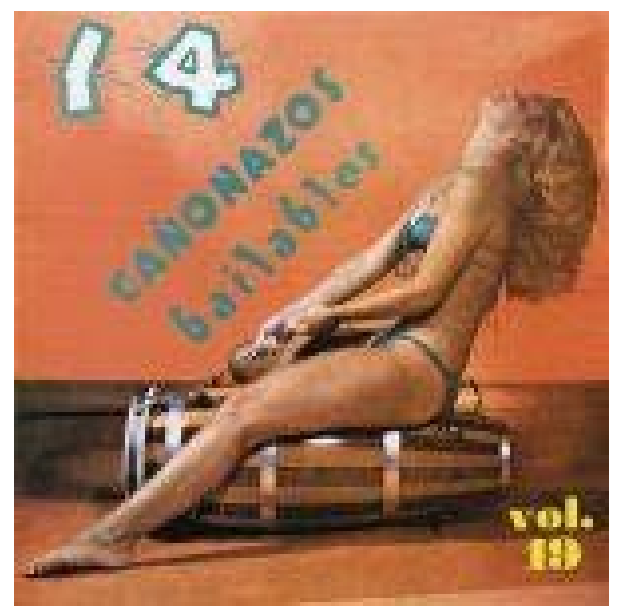

Fig 3. 14 Cañonazos Bailables [Caratula], Discos Fuentes 1979. Tomado de: https:// discosfuentes.com.co/14-canonazos bailables/\#1482124361970-dca66bcf-5ba0

La circunscripción de la imagen publicitaria dentro de la plasticidad de la industria cultural pone de manifiesto su transitoriedad entre prácticas sociales tan disímiles como el entretenimiento y la denuncia. Su carácter herético abandona cualquier disposición al olvido para posicionarse como testimonio etnográfico y antropológico capaz de ser interpretado a través del uso de una hermenéutica de la imagen, permitiendo con esto, comprender la manera en que las sociedades contemporáneas han dramatizado el cuerpo de la mujer y lo han representado a través del signo audiovisual. La publicidad es una metáfora viva de los cuerpos, un archivo críptico que devela los roles construidos socialmente en los últimos años, en un mundo en el que las relaciones industriales adoptan modelos tan heterogéneos como la esclavitud o las vedettes deportivas o artísticas.

Una hermenéutica de la imagen debe centrar su análisis en el conjunto de los medios y de 
las manifestaciones por los cuales los grupos sociales se definen, se sitúan los unos ante los otros y aseguran sus relaciones; esto es, comprender la publicidad como dispositivos ideológicos travestidos por imágenes versátiles que permiten la interpretación figurativa de los cuerpos, los movimientos sociales, los triunfos y las derrotas. Un medio-alegoría que no agota sus intencionalidades, sino que las amplifica en fotogramas.

Partiendo del planteamiento opresióndominación de los cuerpos, un análisis de la imagen publicitaria se constituye como escenario de denuncia del régimen simbólico y cultural del capitalismo del desastre, mostrando a manera de pesquisa, la ingeniería discursiva del establecimiento y su arsenal de estrategias de seducción y usos del signo dentro de la cotidianidad. En este sentido, una arqueología de las carátulas de los 14 Cañonazos Bailables busca descolonizar los espacios, desenmascarar las instituciones resignificar los usos del cuerpo, agenciar la liberación del deseo, para desentramar la manera en que la cultura de masas inocula en el individuoespectador, el gusto larval por el espectáculo $y$ el entretenimiento, fomentando el consumo interminable de bienes, servicios y percepciones de mundo; masificando conductas y serializando acciones.

Por otra parte, la publicidad como acontecimiento de la imagen puede conjurar el carácter pragmático del discurso hegemónico y conferir posibilidad enunciativa a quienes han sido sometidas por el mandato masculino. Es por esto que el análisis de las imágenes se establece como objeto de estudio capaz de fotografiar, fuera de la institucionalidad, el gesto histórico del tiempo, deambulando entre las prácticas de normalización de los cuerpos y los ejercicios transgresivos de la carne. En lo inmediato, esta legítima vanidad pone de relevancia la importancia de analizar la manera en que la publicidad ha teatralizado los discursos de las semióticas de la cotidianidad, conjurando en imágenes de fotográficas, las formas en que se han gestado las diferentes luchas de las mujeres, la visibilización de la otredad, que propende por escenarios participativos y equitativos, el advenimiento de las nuevas ciudadanías; una caja de herramientas audiovisuales que permitirán la comprensión de la esfera social y la resemantización, si es necesario, de los espacios de interacción.

De este modo y partiendo del análisis de las carátulas de los discos 14 Cañonazos Bailables como testimonio histórico, se establece problematizar la noción de cuerpo-objeto bajo perspectivas de las teorías de análisis del discurso y las regulaciones normativas, examinando las diferentes estrategias aplicadas por la sociedad patriarcal, que han permitido la construcción social de los cuerpos, las ideas y los espacios; desde discursos agenciados por regímenes simbólicos, reforzados por la imagen erótico-publicitaria de la Femme fatale, esta entendida como la mujer fatal que usa su sexualidad para atrapar al hombre y las gramáticas de dominación-represión.

Las actuales investigaciones sobre la publicidad han buscado la instalación de prácticas políticas que permitan el debate y la reflexión interdisciplinar frente a temas tan diversos como: las nuevas subjetividades y ciudadanías, la multiculturalidad, los usos contemporáneos del cuerpo, la crisis de las instituciones liberales, la posverdad, la biopolítica, la inteligencia artificial, el sometimiento de la mujer al mandato masculino, las migraciones, entre otros, con la intención de codificar las actuales exigencias sociales y visibilizar discursos imperantes, que van desde el activismo de denuncia promovido por mujeres (las madres de Soacha, Movimiento Me too, Pussy Riot, etc.), movimientos sociales, colectivos artísticos, indígenas y demás grupos que luchan por los derechos de las víctimas del 
capitalismo salvaje, develando sus monstruos y engranajes; pasando por los discursos que refuerzan el establecimiento, originados por los nuevos nacionalismos, los monopolios económicos, el odio al migrante y la eliminación de la otredad, buscando así conjurar la diferencia y promover el statu quo imperante en la sociedad del espectáculo y el entretenimiento. En este sentido, estas investigaciones se han decantado por la exploración narrativa y estética que privilegian el análisis de las diferentes estrategias de gestión instauradas en las sociedades modernas, haciendo uso de la indagación de la cultura Mainstream y sus dispositivos de aculturación programados por la sociedad de la información. Valenzuela (2019), por medio de sus investigaciones de los últimos años, demuestra el viraje de una macro-política a una micro-política en la publicidad dirigidas en territorio latinoamericano, con lo cual se pone la relevancia en la pantalla a personajes marginales y desdibujados que se asumen como sujetos cuestionadores del sistemas político y social, siendo sus cuerpos dispositivos que ponen de manifiesto la experiencia ética y estética del marginado, donde la lucha perpetua entre alma y cuerpo invierte el mito platónico del carro alado para elevarlo sobre el carácter anecdótico de la vida y el bien, y, posicionarlo, sobre las postrimerías de un mal sacralizado por la imagen audiovisual.

\section{REFLEXIONES NECESARIAS}

Las emergentes dinámicas sociales instaladas en el actual mundo globalizado han permitido la consolidación de cambios sociopolíticos, favoreciendo el reconocimiento de derechos a poblaciones y comunidades históricamente relegadas. En este contexto, las mujeres, gracias a sus continuas luchas sociales, han conseguido abrirse paso frente a los privilegios del hombre y el discurso machista que le sostiene, permitiendo, en algunos espacios, cierta equiparabilidad de derechos sociales, políticos y económicos, alcanzando con esto el tan anhelado derecho humano de la Igualdad. Sin embargo, los resultados de este análisis develan que existen diferentes problemáticas sociales que han perdurado por varias generaciones, las cuales generan afectaciones negativas hacía las mujeres, en primer lugar, la cosificación femenina y la progresiva hipersexualización de la mujer, generan degradación en su papel social y la convierten en un objeto comercial, debido a que reduce a las mujeres a un cuerpo sexual, donde la apariencia física es más relevante que otros elementos que integran a la mujer como su personalidad, su capacidad intelectual y su existencia misma como persona, lo que ha llevado en múltiples ocasiones a normalizar y aceptar por parte de las mismas mujeres la naturalización de microviolencias cotidianas en sus entornos tales como exclusión, coerción, invisivilización, imágenes negativas de sí mismas, entre otras. En segundo lugar, el sistema normativo colombiano no responde en su totalidad a las necesidades de garantizar los derechos a las mujeres en un contexto de violencia como el que históricamente ha vivido el país. Adicionalmente, se debe acompañar de medidas pedagógicas preventivas, realizar un mayor y mejor control del tipo de contenidos disponibles en los diferentes entornos en los que se muestra a la mujer como un objeto de consumo, (publicidad, medios de comunicación, industria musical, etc.).

\section{REFERENCIAS BIBLIOGRÁFICAS}

Acosta Alvarado, P. (2007). La protección de los derechos de las mujeres en la Constitución colombiana. Derecho del Estado, 49-60. DOI: https://doi. org/10.22370/ rcs.2015.66.208 
Álvaro, J y Fernández, B. (2006). Representaciones sociales de la mujer. Athenea Gigital, 9, 65-77. Disponible en http://antalya.uab.es/athenea/num9/ alvaro.pdf

Arosomera R, (2016). Machismo y cosificación de la mujer: un flagelo social. Recuperado de https://www.psyciencia.com/machismocosificacion/

Bobbio, N. (1997). Teoría general del derecho. Segunda reimpresión de la segunda edición. Bogotá D. C., Colombia: Temis.

Chacon, P. (2008). La mujer como objeto sexual en la publicidad. Revista Científica de Educomunicación Comunicar. $\mathrm{n}^{\circ}$ 31. v. XVI. [En línea: http://biblioteca. universia.net/html_bura/ficha/params/ title/mujercomo-objeto-sexuapublicidad/ id/52001865.html]

Consejería para la Equidad de la Mujer. (2014). Consejería Equidad Mujer. Obtenido de http://www.equidadmujer. gov.co/consejeria/Paginas/preguntasfrecuentes.aspx

Grande-López, Víctor. (2019). La hipersexualización femenina en los medios de comunicación como escaparate de belleza y éxito. Recuperado de https:// acortar.link/9ZLFW9

González, A y Rorrado E. (2018). Cosificación y mercantilización de las mujeres: las tecnologías como instrumento de violencia. Recuperado de https://uvadoc. uva.es/handle/10324/32491
Irigaray, L. (2009). Ese sexo que no es uno. Ediciones Akal: Madrid.

Lagarde, M. (2006). Pacto entre mujeres : sororidad. Revista Aportes. Edición 25. Equidad de género. Asociación de Administradores Gubernamentales. Buenos Aires. Recuperado de https://www. asociacionag.org.ar/pdfaportes/25/09.pdf

Lerner, G. (1986). La creación del patriarcado. Recuperado de https://www. antimilitaristas.org//MG/pdf/la_creacion_ del_patriarcado_-_gerda_lerner-2.pdf

Lopez, V (2019). La hipersexualización femenina en los medios de comunicación como escaparate de belleza y éxito. Recuperado de https://www. researchgate.net/publication/334580876 La_hipersexualizacion_femenina_en_ los_medios_de_comunicacion_como_ escaparate_de_belleza_y_exito

Muñoz López, A. M. (2014). La imagen corporal en la sociedad del siglo XXI. [Trabajo de Fin de Grado]. Grado en enfermería. Facultad de Medicina y Ciencias de la Salud. Universidad Internacional de Cataluña.

Navarro, O., y Restrepo, D. (2013). Representaciones Sociales: perspectivas teóricas y metodológicas. CES Psicología, 6(1), 1-4. Retrieved May 24, 2020, Recuperado http://www.scielo.org.co/ scielo.php?script=sci_arttext\&pid=S2011$30802013000100001 \&$ lng=en\&tlng=es. 
Piconne, M. (2018). Filosofía, política, justicia y género. Aproximación al pensamiento de Platón y Rousseau en torno a las mujeres. Derechos en acción, 132-154.

Segato, L (2006) La escritura en el cuerpo de las mujeres asesinadas en Ciudad Juárez. 1a. ed. - Buenos Aires. Recuperado de http://www.feministas.org/IMG/pdf/rita_ segato_.pdf.

Segato, L (2016). La guerra contra las mujeres, Barcelona, España: Traficantes de Sueños

Sotelo \& Dominguez (2014). Cosificación Femenina en la Era del Capitalismo Tardío. Recuperado de https://www. uv.mx/iiesca/files/2014/09/05CA201401. pdf

Valenzuela, J. (2019). Aproximaciones a la práctica clínica de los equipos de eQtasis desde el enfoque de género. Disponible en http:// repositorio.uchile.cl/handle/2250/176594

Walter, N. (2010). Muñecas vivientes. El regreso del sexismo. Madrid: Turner Publicaciones. 